\title{
ORIGINAL
}

\section{Postoperative nausea and vomiting following lower limb surgery : a comparison between single-injection intraarticular anesthesia and continuous epidural anesthesia}

\author{
Yuta Uemura ${ }^{1}$, Yoko Sakai ${ }^{1}$, Yasuo M. Tsutsumi ${ }^{2}$, Nami Kakuta ${ }^{1}$, Chiaki Murakami ${ }^{1}$, Shiho Satomi ${ }^{1}$, Takuro Oyama ${ }^{1}$, \\ Naohiro Ohshita ${ }^{3}$, Tomoya Takasago ${ }^{4}$, Daisuke Hamada ${ }^{4}$, Koichi Sairyo ${ }^{4}$, and Katsuya Tanaka ${ }^{1}$ \\ ${ }^{1}$ Department of Anesthesiology, Tokushima University, Tokushima JAPAN, ${ }^{2}$ Department of Anesthesiology and Critical Care, Graduate School \\ of Biomedical and Health Sciences, Hiroshima University, Hiroshima JAPAN, ${ }^{3}$ Department of Anesthesiology, Osaka Dental University, \\ Osaka JAPAN, ${ }^{4}$ Department of Orthopedics, Institute of Biomedical Sciences, University of Tokushima Graduate School, Tokushima, JAPAN
}

\begin{abstract}
Study Objective : the incidence of postoperative nausea and vomiting (PONV) following single-injection intraarticular anesthesia was compared to that following continuous epidural anesthesia. Design : Prospective, double-blind, randomized study. Setting : University-affiliated teaching hospital. Patients : Forty-eight patients finally participated in this study, and each group contained twenty-four patients. Interventions : Patients scheduled to undergo lower limb surgery under general anesthesia were randomly allocated into two groups, to receive either single-injection intraarticular or continuous epidural anesthesia for postoperative analgesia. Measurements : The incidence and severity of PONV, complete response rates (i.e., no vomiting or rescue antiemetic use), and pain scores were recorded 2, 24, and $48 \mathrm{~h}$ postoperatively. Main results : No significant differences between groups were observed in the incidence and severity of PONV, rescue antiemetic use, or complete response rate at any of the time points, but only the use of rescue analgesics was significantly less in continuous epidural anesthesia group during the $2-24 \mathrm{~h}$ postoperative period $(\mathrm{P}=0.04)$. Conclusion : While the use of single-injection intraarticular anesthesia following lower limb surgery did not prevent PONV more than continuous epidural anesthesia in this study, the intraarticular technique still provides greater simplicity, safety, and cost-effectiveness. J. Med. Invest. 66:303-307, August, 2019
\end{abstract}

Keywords : PONV, intraarticular injections, epidural anesthesia

\section{INTRODUCTION}

Postoperative nausea and vomiting (PONV) is a distressing complication that can adversely affect patient recovery ; it frequently delays patient discharge from the post-anesthesia care unit and is the leading cause of unexpected hospital admission following planned ambulatory surgery (1). PONV is considered by many patients to be more distressing than postoperative pain (2). The general incidence of PONV is approximately $50 \%$ and in a subset of high-risk patients, PONV rates can be as high as $70 \%(3,4,5,6)$. The four main risk factors of PONV include the female sex, a history of PONV or motion sickness, being a nonsmoker, and the use of postoperative opioids (7).

Immediate postoperative pain following lower limb surgery can be severe and sometimes difficult to manage. Postoperative pain relief can be achieved using a variety of techniques, such as intravenous analgesia, epidural analgesia, peripheral nerve blocks, and local anesthetic infiltration. Effective treatment of postoperative pain and controlling side effects are important to enable early rehabilitation and hospital discharge following lower limb surgery (8). Continuous epidural analgesia has been shown to provide better pain relief than systemic opioid administration, but is associated with significant side effects, including nausea, urinary retention, hypotension, and delayed mobilization.

Received for publication February 26, 2019 ; accepted June 27, 2019. Uemura and Sakai contributed equally to this work.

Address correspondence and reprint requests to Nami Kakuta, MD, $\mathrm{PhD}$, Department of Anesthesiology, Tokushima University, 3-18-15, Kuramoto, Tokushima 770-8503, JAPAN and Fax : +81-88-633-7182
Furthermore, use of epidural analgesia may delay initiation of anticoagulant thromboprophylaxis due to the potential risk of epidural hematoma $(8,9)$. Local infiltration of analgesics combined with a single-injection or continuous infusion of local anesthetics at the surgical site has been reported as an alternative method for achieving effective postoperative pain relief $(10,11)$. Additionally, various combinations of drugs and local infiltration techniques (i.e., drug mixture, and the use of a wound catheter) have been evaluated $(11,12,13)$. Among them, use of the intraarticular analgesic method has been shown to potentially reduce the occurrence of side effects while maintaining adequate pain relief and maximum muscle control. However, these studies have provided conflicting results owing to their differing study designs $(14,15,16,17,18)$.

Since intraarticular anesthesia is administered by the surgeon intraoperatively and acts locally, we predicted that the rate of complications following intraarticular anesthesia may be less than that of other methods. Therefore, the purpose of this study was to compare the incidence of PONV following the use of intraarticular local anesthesia to that following continuous epidural anesthesia, after lower limb surgery.

\section{PATIENTS AND METHODS}

The current prospective study was approved by the Human Research Ethics Committee of Tokushima University Hospital and registered in the clinical trials database (UMIN000019978). Informed consent was obtained from all patients, and the study was conducted in accordance with the principles outlined in the Declaration of Helsinki. 
Patients aged 30-85 years, with an American Society of Anesthesiologists (ASA) physical status of I-III, that were scheduled to undergo lower limb surgery (total knee arthroplasty, total hip arthroplasty, or rotational acetabular osteotomy) under general anesthesia were enrolled in this prospective study between November 2015 and July 2016. The patients' information, including their sex, history of PONV and/or motion sickness, and smoking status, was recorded. The exclusion criteria were as follows : an ASA physical status of $\mathrm{I}$, abnormal liver and/or renal function, or use of antiemetics.

No preanesthetic medication was administered. All patients were monitored using electrocardiography, noninvasive arterial blood pressure, pulse oximetry, and capnography. General anesthesia was induced with remifentanil, propofol, and rocuronium to facilitate endotracheal intubation, and was maintained using volatile anesthetics (sevoflurane 1-2\% and desflurane $4-6 \%$ ) in oxygen, with a mixture of remifentanil $0.1-0.5 \mu \mathrm{g} / \mathrm{kg} / \mathrm{min}$ and fentanyl $0-100 \mu \mathrm{g}$. Incremental doses of rocuronium were administered, as necessary, for neuromuscular blockade, the effects of which were reversed using sugammadex $2 \mathrm{mg} / \mathrm{kg}$ upon surgery completion.

Prior to undergoing surgery, the patients were randomly allocated into one of two groups according to which postoperative analgesia method they were to receive : single-injection intraarticular anesthesia or continuous epidural anesthesia. The patients that received intraarticular anesthesia (i.e., Group I) were administered ropivacaine $200 \mathrm{mg}$ and dexamethasone $6.6 \mathrm{mg}$, mixed with sterile normal saline to comprise a combined volume of $40 \mathrm{~mL}$. Patients that were to receive continuous epidural anesthesia (i.e., Group E) underwent epidural catheter placement at either L2-3 or L3-4, followed by epidural administration of fentanyl $0.1 \mu \mathrm{g} / \mathrm{kg} / \mathrm{ml}$, total $10 \mathrm{ug} / \mathrm{kg}$ and local anesthetic $(0.125 \%$ levobupivacaine, $2-4 \mathrm{ml} / \mathrm{h}$ ) ; this was maintained for $>48 \mathrm{~h}$. A rescue analgesic (dicrofenac sodium $25 \mathrm{mg}$ sup. or loxoprofen sodium $60 \mathrm{mg}$ p.o.) was administered upon patient request for both groups. Intravenous metoclopramide $(10 \mathrm{mg})$ was administered as a rescue antiemetic when necessary.
The incidence and severity of PONV, complete response rate, and the patients' pain scores (using a visual analog scale [VAS]) were recorded 2, 24, and $48 \mathrm{~h}$ after surgery by blinded observers. The severity of nausea was recorded using the following scale : 0 , absence of nausea; 1 , mild nausea; 2 , moderate nausea ; or 3 , severe nausea. The complete response rate was defined as no occurrence of vomiting and no rescue antiemetic use. The patients' analgesic demands were also recorded.

\section{Statistical analysis}

Statistical analyses were performed using SPSS software, version 22 (SPSS Inc., Chicago, IL, USA). The data are expressed as the mean \pm standard deviation (SD). $P$ values $<0.05$ were considered statistically significant without any adjustment for multiplicity of testing.

The t-test, $\chi^{2}$ test, and Fisher's exact test were used to analyze the patient demographics, cumulative incidence of vomiting at each time point, rescue antiemetic use, complete response rate, and VAS pain scores. The Mann-Whitney U test was used to analyze the nausea severity scores.

\section{RESULTS}

Of 53 patients considered eligible for the study, 3 refused and 50 agreed to participate. One patient was excluded due to the operation being called off and one patient was excluded to occlusion of the epidural catheter (Figure 1). Twenty-four patients received intraarticular anesthesia (Group I), and 24 received continuous epidural anesthesia (Group E). The demographic data were similar for both groups with respect to age, sex, weight, ASA physical status, smoking status, and history of motion sickness and PONV. Similarly, there were no differences in the durations of anesthesia or surgery, or the amount of blood loss (Table 1).

There were no significant differences observed in the incidence of PONV, nausea severity scores, rescue antiemetic use, or complete response rate between the two groups at any time point

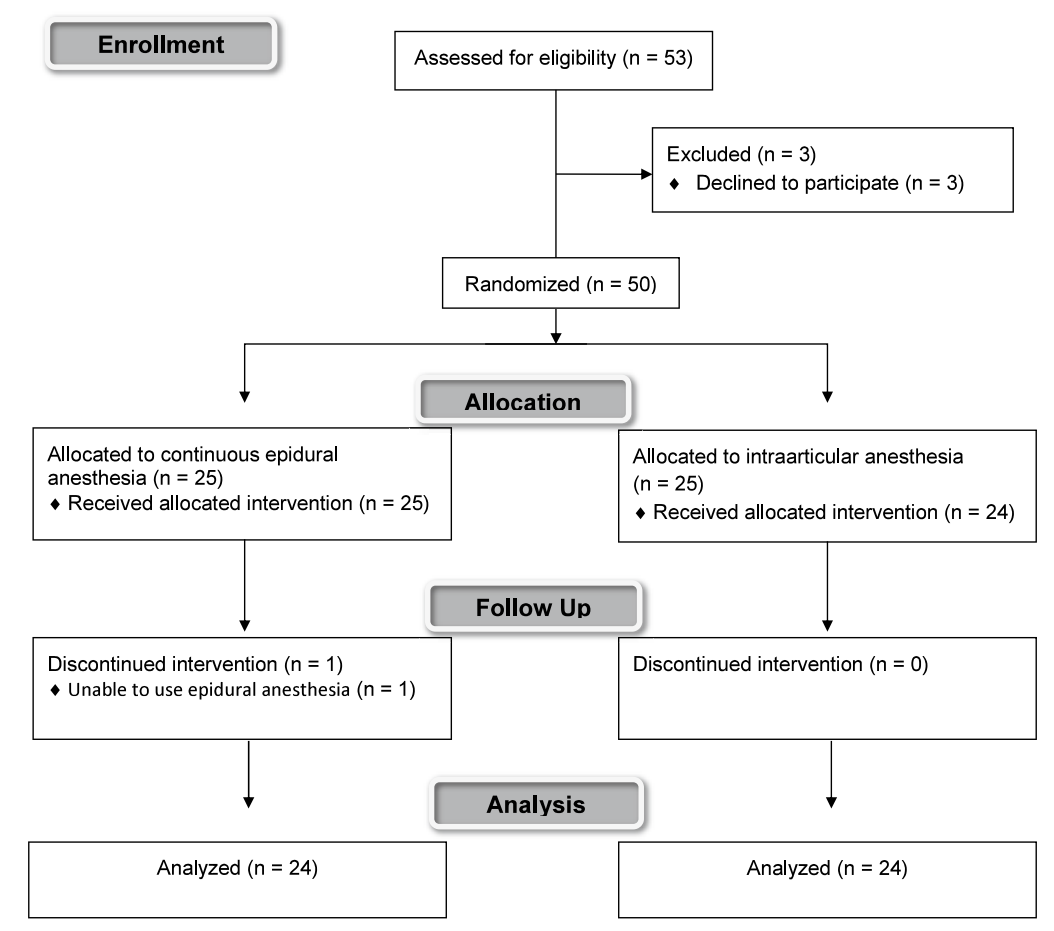

Figure 1. CONSORT flow chart showing the selection process for patients. 
(Table 2). The VAS pain scores were also not significantly different between the groups; however, the use of rescue analgesics was significantly less in Group E during the 2-24-h postoperative period (Table 3).

Table 1. Patient demographic and perioperative data

\begin{tabular}{lcc}
\hline & $\begin{array}{c}\text { Group I } \\
(\mathrm{n}=24)\end{array}$ & $\begin{array}{c}\text { Group E } \\
(\mathrm{n}=24)\end{array}$ \\
\hline Patients & & \\
Age (years) & $67.1 \pm 9.6$ & $60.5 \pm 13.9$ \\
Sex (Male : Female) & $8: 16$ & $7: 17$ \\
Height (cm) & $154.0 \pm 7.1$ & $157.6 \pm 7.2$ \\
Weight (kg) & $58.6 \pm 11.0$ & $60.7 \pm 13.3$ \\
ASA physical status (I/II/III) & $3 / 19 / 2$ & $7 / 16 / 1$ \\
Risk factors & & \\
Smoker & 1 & 1 \\
History of motion sickness & 2 & 3 \\
History of PONV & 3 & 4 \\
Surgery-/anesthesia-related parameters & & \\
Duration of anesthesia (min) & $248.5 \pm 57.8$ & $256.3 \pm 49.8$ \\
Duration of surgery (min) & $180.1 \pm 59.4$ & $189 \pm 66.0$ \\
Blood loss (ml) & $429.5 \pm 393.6$ & $487.0 \pm 442.8$ \\
Type of surgery (Hip : Knee) & $18: 6$ & $22: 2$ \\
$\quad$ Total hip arthroplasty & 17 & 20 \\
$\quad$ Rotational acetabular osteotomy & 1 & 2 \\
$\quad$ Total knee arthroplasty & 6 & 2 \\
\hline
\end{tabular}

Data are presented as the mean \pm standard deviation, or number (n).

Group I, intraarticular anesthesia group ; Group E, continuous epidural anesthesia group ; ASA, American Society of Anesthesiologists ; PONV, postoperative nausea and vomiting.

Table 2. Postoperative parameters

\begin{tabular}{lccc}
\hline & $\begin{array}{c}\text { Group I } \\
(\mathrm{n}=24)\end{array}$ & $\begin{array}{c}\text { Group E } \\
(\mathrm{n}=24)\end{array}$ & $P$-value \\
\hline 0-2-h Postoperative period & & & \\
PONV & 5 & 6 & $P=0.36$ \\
Vomiting (no. of episodes) & 4 & 8 & $P=0.37$ \\
Nausea scores (0/1/2/3) & $19 / 1 / 0 / 4$ & $18 / 0 / 1 / 5$ & $P=0.71$ \\
Rescue antiemetic use & 4 & 2 & $P=0.33$ \\
Complete response (\%) & $20(83 \%)$ & $19(79 \%)$ & $P=0.5$ \\
2-24-h Postoperative period & & & \\
PONV & 2 & 6 & $P=0.12$ \\
Vomiting (no. of episodes) & 0 & 4 & $P=0.10$ \\
Nausea scores (0/1/2/3) & $22 / 0 / 1 / 1$ & $18 / 1 / 3 / 2$ & $P=0.14$ \\
Rescue antiemetic use & 1 & 2 & $P=0.5$ \\
Complete response (\%) & $23(96 \%)$ & $21(88 \%)$ & $P=0.3$ \\
24-48-h Postoperative period & & & \\
PONV & 1 & 4 & $P=0.17$ \\
Vomiting (no. of episodes) & 0 & 2 & $P=0.16$ \\
Nausea scores (0/1/2/3) & $23 / 0 / 1 / 0$ & $20 / 2 / 0 / 2$ & $P=0.16$ \\
Rescue antiemetic use & 1 & 1 & $P=0.76$ \\
Complete response (\%) & $23(96 \%)$ & $22(92 \%)$ & $P=0.5$
\end{tabular}

Data are presented as the number of patients (percentile), unless otherwise stated.

Group I, intraarticular anesthesia group ; Group E, continuous epidural anesthesia group ; PONV, postoperative nausea and vomiting. Nausea scores : 0 , absence of nausea ; 1 , mild nausea $; 2$, moderate nausea; or 3 , severe nausea.
Table 3. Postoperative pain data

\begin{tabular}{lccc}
\hline & $\begin{array}{c}\text { Group I } \\
(\mathrm{n}=24)\end{array}$ & $\begin{array}{c}\text { Group E } \\
(\mathrm{n}=24)\end{array}$ & $P$-value \\
\hline 0-2-h Postoperative period & & & \\
Rescue analgesic use (\%) & $9(38 \%)$ & $10(42 \%)$ & $P=0.5$ \\
VAS pain score & $4.4 \pm 3.5$ & $4.5 \pm 4.1$ & $P=0.91$ \\
2-24-h Postoperative period & & & \\
Rescue analgesic use (\%) & $13(54 \%)$ & $6(25 \%)$ & $P=0.04^{\#}$ \\
VAS pain score & $2.3 \pm 2.0$ & $2.3 \pm 2.7$ & $P=0.9$ \\
24-48-h Postoperative period & & & \\
Rescue analgesic use (\%) & $9(38 \%)$ & $7(29 \%)$ & $P=0.38$ \\
VAS pain score & $1.4 \pm 1.9$ & $2.5 \pm 2.6$ & $P=0.10$ \\
\hline
\end{tabular}

Data are presented as the number of patients (percentile) or the mean \pm standard deviation.

Group I, intraarticular anesthesia group ; Group E, continuous epidural anesthesia group ; VAS, visual analog scale $(0$, no pain ; to 10 , the worst pain imaginable).

\section{DISCUSSION}

In this study, we compared the intraarticular injection technique with continuous epidural infusion for postoperative analgesia, and found no significant differences in the incidence or severity of PONV, complete response rate, or the use of rescue antiemetics between the two methods. The benefits of intraarticular analgesia have been evaluated previously, primarily with patients having underwent knee surgery ; a systematic review of previous studies demonstrated evidence of reduced pain during the immediate and early postoperative periods following intraarticular local anesthesia after knee surgery $(15,18)$. However, some studies have demonstrated the effectiveness of intraarticular analgesia following hip surgery $(11,12)$. In the current study, we included patients undergoing knee or hip surgery, and found that intraarticular analgesia was effective for pain management following both types of surgery.

We noted that there was a significant difference between the two study groups regarding the use of rescue analgesics during the 2-24-h postoperative period. Since single-injection intraarticular analgesia only remains effective short period $(19,20)$, it is reasonable that patients in Group I required rescue analgesia more often than those in Group E. However surgical site, knee or hip, and the invasiveness, i.e. total knee arthroplasty $>$ total hip arthroplasty, may influence on the results for the use of rescue analgesics. Although, there was no statistically significant difference, Group I tended to have more knee surgery than Group E. Use of continuous wound catheters may reduce the need for rescue analgesics ; however, we chose not to utilize them in the present study owing to concerns regarding the possible increased risks of infection and delayed wound healing $(8,21)$. Previous studies investigating the efficacy of local infiltration analgesia after knee surgery did not demonstrate an increased frequency of infections, but the follow-up periods in these studies were very limited $(10,22,23)$. Therefore, it should be further investigated whether combining intraarticular injections and continuous infusion of local anesthesia to surgical sites can provide more effective pain control than traditional methods.

Ropivacaine is a relatively new, long-acting, aminoamide local anesthetic agent (24) that is chemically homologous to bupivacaine and mepivacaine (25). It demonstrates similar clinical efficacy to racemic bupivacaine, but is less cardio- and neurotoxic, and induces less vasodilation. The peak plasma concentration of ropivacaine following intraarticular administration has been 
shown to be proportional to the dose administered, and remains below the recognized toxicity level after administration of 200 $\mathrm{mg}(19,20)$. Therefore, we chose to administer $200 \mathrm{mg}$ of ropivacaine for intraarticular anesthesia in our study.

A few previous studies have quantified the incidence of PONV after intraarticular analgesia ; Lykoudi et al. (26) found no significant difference between ropivacaine and a placebo, and Rautoma et al. (27) reported that the incidence PONV for patients that received ropivacaine was lower than that of those who received a placebo. However, intraarticular ropivacaine and morphine administration has been associated with a higher incidence of PONV (16), but these study participants were only observed for a short period (24-h). In the present study, we did not observe any significant reduction in PONV during the 48-h postoperative period.

This study had several limitations. First, we did not define the dose of fentanyl for continuous epidural anesthesia, which may have affected the study's results. Second, dexamethasone was used as an adjuvant drug in the intraarticular analgesia group. Dexamethasone is a potent and highly selective glucocorticoid with minimal mineralocorticoid effects. It inhibits nociceptive impulse transmission along myelinated C-fibers, and when combined with local anesthetics, it increases the duration of regional blocks $(28,29)$. Intraarticular ropivacaine has only been shown to be effective when it is administered with other drugs, not when used alone (15) ; therefore, dexamethasone was used in this study to increase analgesic efficacy. The corticosteroid dexamethasone effectively prevents nausea and vomiting in postoperative patients. However, in this study, it may have acted locally via steroid receptors, it could not have acted systemically; therefore, it could not prevent PONV. Finally, antiemetic use was restricted to only metoclopramide in this study ; however, use of other antiemetics may have reduced PONV.

In conclusion, the use of single-injection intraarticular anesthesia following lower limb surgery did not prevent PONV more than continuous epidural anesthesia in this study. However, the greater simplicity, safety, and cost effectiveness of the intraarticular technique is apparent. Therefore, further studies are needed to further decrease the incidence of PONV.

\section{CONFLICTS OF INTEREST}

Each author declares that they have no conflicts of interest associated with this study or manuscript.

\section{ACKNOWLEDGEMENTS}

This study was supported entirely by JSPS KAKENHI (Grant Number 18K16483).

\section{REFERENCES}

1. Parra-Sanchez I, Abdallah R, You J, Fu AZ, Grady M, Cummings $\mathrm{K} 3^{\text {rd }}$, Apfel C, Sessler DI : A-time motion economic analysis of postoperative nausea and vomiting in ambulatory surgery. Can J Anaesth 59 : 366-375, 2012

2. Macario A, Weinger M, Carney S, Kim A: Which clinical anesthesia outcomes are important to avoid? The perspective of patients. Anesth Analg 89:652-658, 1999

3. Kakuta N, Tsutsumi YM, Horikawa YT, Kawano H, Kinoshita M, Tanaka K, Oshita S : Neurokinin-1 receptor antagonism, aprepitant, effectively post-operative nausea and vomiting while increasing analgesic tolerance in laparoscopic gynecological procedures. J Med Invest 58: 246-251, 2011

4. Tsutsumi YM, Kakuta N, Soga T, Kume K, Hamaguchi E, Tsutsumi R, Tanaka K : The effects of intravenous fosaprepitant and ondansetron for the prevention of postoperative nausea and vomiting in neurosurgery patients : a prospective, randomized, double-blinded study. Biomed Res Int 2014 : 307025(1-6), 2014.

5. Soga T, Kume K, Kakuta N, Hamaguchi E, Tsutsumi R, Kawanishi R, Fukuta K, Tanaka K, Tsutsumi YM : Fosaprepitant versus ondansetron for the prevention of postoperative nausea and vomiting in patients who undergo gynecologic abdominal surgery with patient-controlled epidural analgesia : a prospective, randomized, double-blind study. J Anesth 29:696-701, 2015.

6. Kakuta N, Kume K, Hamaguchi E, Tsutsumi R, Mita N, Tanaka K, Tsutsumi YM : The effects of intravenous fosaprepitant and ondansetron for the prevention of postoperative nausea and vomiting in patients who undergo lower limb surgery. -A prospective, randomized, double-blind study- J Anesth 29:836-841, 2015.

7. Apfel CC, Läärä E, Koivuranta M, Greim CA, Roewer N : A simplified risk score for predicting postoperative nausea and vomiting : conclusions from cross-validations between two centers. Anesthesiology $91: 693-700,1999$

8. Anderson KV, Bak M, Christensen BV, Harazuk J, Pedersen NA, Soballe K: A randomized, controlled trial comparing local infiltration analgesia with epidural infusion for total knee arthroplasty. Acta Orthop 81 : 606-610, 2010

9. Choi PT, Bhandari M, Scott J, Douketis J : Epidural anesthesia for pain relief following hip or knee replacement. Cochrane Database Syst Rev : CD003071, 2003

10. Vendittoli PA, Makinen P, Drolet P, Lavigne M, Fallaha M, Guertin MC, Varin F : A multimodal analgesia protocol for total knee arthroplasty. A randomized, controlled study. J Bone Joint Surg Am 88 : 282-289, 2006

11. Anderson LØ, Kehlet H : Analgesic efficacy of local infiltration analgesia in hip and knee arthroplasty : a systematic review. Br J Anaesth 113 : 360-374, 2014

12. Anderson KV, Pfeiffer-Jensen M, Haraldstad V, Søballe $\mathrm{K}$ : Reduced hospital stay and narcotic consumption, and improved mobilization with local and intraarticular infiltration after hip arthroplasty : a randomized clinical trial of an intraarticular technique versus epidural infusion in 80 patients. Acta Orthop 78:180-186, 2007

13. Kerr DR, Kohan L : Local infiltration analgesia : a technique for the control of acute postoperative pain following knee and hip surgery : a case study of 325 patients. Acta Orthop 79: 174-182, 2008

14. Browne C, Copp S, Reden L, Pulido P, Colwell C Jr : Bupivacaine bolus injection versus placebo for pain management following total knee arthroplasty. J Arthroplasty 19 : 377380, 2004

15. Rosen AS, Colwell CW, Pulido PA, Chaffee TL, Copp SN : A randomized controlled trial of intraarticular ropivacaine for pain management immediately following total knee arthroplasty. HSS J 6 : 155-159, 2010

16. Tanaka N, Sakahashi H, Sato E, Hirose K, Ishii S : The efficacy of intra-articular analgesia after total knee arthroplasty in patients with rheumatoid arthritis and in patients with osteoarthritis. J Arthroplasty 16 : 306-311, 2001

17. Zhou Y, Yang TB, Wei J, Zeng C, Li H, Yang T, Lei GH : Single-dose intra-articular ropivacaine after arthroscopic knee surgery decreases post-operative pain without increasing side effects : a systematic review and meta-analysis. Knee Surg Sports Traumatol Arthrosc 24 : 1651-1659, 2016 
18. Møiniche S, Mikkelesen S, Wetterslev J, Dahl JB : A systematic review of intra-articular local anesthesia for postoperative pain relief after arthroscopic knee surgery. Reg Anesth Pain Med 24 : 430-437, 1999

19. Convery PN, Milligan KR, Quinn P, Sjövall J, Gustafsson $\mathrm{U}$ : Efficacy and uptake of ropivacaine and bupivacaine after single intra-articular injection in the knee joint. Br J Anaesth $87: 570-576,2001$

20. Chen S,Chen Z, Jin Y, Tian Z, Lin X, Zhu M, Xu S, Lin J, Xu $\mathrm{J}$ : Pharmacokinetics and efficacy of ropivacaine in Chinese patients following intra-articular administration. Int J Clin Pharmacol Ther $51: 393-400,2013$

21. Liu SS, Richman JM, Thirlby RC, Wu CL : Efficacy of continuous wound catheters delivering local anesthetic for postoperative analgesia : A quantitative and qualitative systematic review of randomized controlled trials. J Am Coll Surg 203 : 914-932, 2006

22. Bianconi M, Ferrano L, Traina GC, Zanoli G, Antonelli T, Guberti A, Ricci R, Massari L: Pharmacokinetics and efficacy of ropivacaine continuous wound instillation after joint replacement surgery. Br J Anaesth 91 : 830-835, 2003

23. Dobrydnjov I, Anderberg C, Olsson C, Shapurova O, Angel $\mathrm{K}$, Bergman S : Intraarticular vs.extraarticular ropivacaine infusion following high-dose local infiltration analgesia after total knee arthroplasty. Acta Orthop 82 : 692-698,2011

24. McClure JH : Ropivacaine. Br J Anaesth 76 : 300-307, 1996

25. Knudsen K, Beckman Suurküla M, Blomberg S, Sjövall J, Edvardsson N : Central nervous and cardiovascular effects of i.v. infusions of ropivacaine, bupivacaine and placebo in volunteers. Br J Anaesth 78: 507-514, 1997

26. Lykoudi I, Kottis G, Nikolaou VS, Setaki P, Fassoulaki A, Efstathopoulos N : Intra-articular morphine enhances analgesic efficacy of ropivacaine for knee arthroscopy in ambulatory patients. Orthopedics $34: 91,2011$

27. Rautoma P, Santanen U, Avela R, Luurila H, Perhoniemi V, Erkola O : Diclofenac premedication but not intra-articular ropivacaine alleviates pain following day-case knee arthroplasty. Can J Anaesth 47 : 220-224, 2000

28. Bhattacharjee DP, Biswas C, Haldar P, Ghosh S, Piplai G, Rudra JS : Efficacy of intraarticular dexamethasone for postoperative analgesia after arthroscopic knee surgery. J Anaesthesiol Clin Pharmacol 30 : 387-390, 2014

29. Johansson A, Hao J, Sjölund B : Local corticosteroid application blocks transmission in normal nociceptive C-fibers. Acta Anaesthesiol Scand 34 : 335-338, 1990 